\title{
Whether Innovation Factor Investment Can Promote Green Economy Development-An Empirical Study Based on Panel Data of 30 Provinces in China
}

\author{
Shuying Wang ${ }^{1,}$, , Jingjing $\mathrm{Kou}^{2, \mathrm{~b},{ }^{*}, \text { Zhaorong Wei }} \mathrm{i}^{3, \mathrm{c}}$ \\ ${ }^{1}$ School of management engineering, Zhengzhou university, Henan, China \\ ${ }^{2}$ School of management engineering, Zhengzhou university, Henan, China \\ ${ }^{3}$ School of management engineering, Zhengzhou university, Henan, China \\ awangshuying@zzu.edu.cn, bangelakou1994@126.com, 623137783 @qq.com
}

Keywords: Innovation factor input, Green economy efficiency, Space spillover effect.

\begin{abstract}
Based on the panel data of 30 provinces from 2009 to 2016, this paper uses the spatial Dubin model to study the relationship between regional innovation factor input (R\&D personnel input and R\&D capital input) and green economy efficiency, the spatial spillover characteristics of green economy efficiency, and the direct and indirect effects of innovation factor input. The results showed that the input of innovation personnel had no significant effect on the development of green economy in the region, but had an indirect positive effect on the development of green economy in the neighboring region. Innovative capital investment can directly promote the development of green economy in the region, but indirectly inhibit the development of green economy in the neighboring region, and the inhibition effect on the neighboring region is greater than the promotion effect on the region. In addition, the impact of foreign direct investment and urbanization on the efficiency of green economy is not significant, and the level of economic development can promote the efficiency of green economy in neighboring areas.
\end{abstract}

\section{创新要素投入是否能促进绿色经济发展一基于中国30省面板数据的实}

\author{
证研究

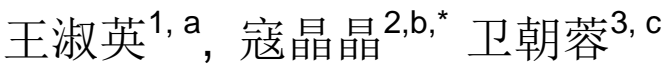 \\ 1郑州大学管理工程学院, 郑州, 河南, 中国 \\ 2郑州大学管理工程学院, 郑州, 河南, 中国 \\ 3 郑州大学管理工程学院, 郑州, 河南, 中国 \\ awangshuying@zzu.edu.cn, bangelakou1994@126.com, '23137783 @qq.com \\ “通讯作者
}

关键词：创新要素投入; 绿色经济效率; 空间溢出效应

中文摘要. 本文基于2009-2016年全国30省的面板数据, 运用空间杜宾模型对区域创新要素投 入 $(R \& D$ 人员投入和 $R \& D$ 资本投入 $)$ 与绿色经济效率的关系、绿色经济效率的空间溢出特征、 创新要素投入的直接和间接效应进行研究。结果发现：创新人员投入对本地区绿色经济发展 无显著作用，但对邻近地区绿色经济发展有间接正向促进作用；创新资本投入对本地区绿色 经济发展有直接促进作用，但能间接抑制邻近地区绿色经济发展，且对临近地区的抑制作用 
大于对本地区的促进作用。此外，外商直接投资和城市化进程对绿色经济效率的影响作用不 显著, 经济发展水平能够促进邻近地区绿色经济效率的提升。

\section{1. 引言}

新中国成立70年来，经济发展取得举世瞩目的成就，但在经济高速增长的同时，环境污 染和能源消耗过度等问题也日益严峻, 而资源和环境一方面能促进经济增长, 同时也是经济 增长速度和规模的硬性制约条件, 如果一味追求经济增长而忽略环境污染, 将会扭曲经济增 长绩效评价从而误导政策建议 ${ }^{[1]}$ 。在此背景下, 我国中共中央政治局审议通过《关于加快推进 生态文明建设的意见》，意见指出要推进新型工业化、城镇化、信息化、农业化、现代化和 绿色化协同发展，这为未来中国经济发展模式转向“绿色化”提供政策引导和方向。绿色经济 以高新技术为依托, 是市场化与生态化有机结合、充分体现自然资源价值和生态价值的经济, 也是经济高质量发展的重要支撑。绿色经济发展的重要指标是绿色经济效率 (Green Economic Efficiency），在传统经济效率评价的基础上增加对非期望产出的分析，综合考虑了经济增长 和生态环境改善。绿色经济效率的提升关键在于科技创新, 科技创新是缓解区域经济发展与 环境污染、资源浪费矛盾、推动经济绿色化发展的主要驱动力, 也是实现中国经济可持续发 展的必然选择。创新要素作为科技创新的资源支撑，必然对绿色经济发展产生重大影响，尤 其在国家实施创新发展战略的推动下, 各地区依据自身要素禀赋条件优化创新环境, 创新要 素 (创新人员、创新资本) 作为提升中国科技竞争力的重要保障，成为地区间竞相争夺的战 略资源。那么创新要素投入如何影响绿色经济效率？创新要素投入是否存在空间溢出效应? 这是本文将要解决的问题。

众多学者对绿色经济效率进行了广泛而深入的研究, 通过梳理相关文献可以发现这些研 究要集中于两各方向:一是绿色经济效率的测算, 二是绿色经济效率的影响因素分析。其中, 关于绿色经济效率测算的研究主要有: 叶仁道 ${ }^{[2]}$ 基于偏正态面板数据模型测算中国29省的绿 色经济效率并研究了中国绿色经济效率的影响因素; 聂玉立 ${ }^{[3]}$ 建立受限因变量回归模型分析 中国地级以上城市的绿色经济效率区域性差异; 张军 ${ }^{[4]}$ 以广东省为例, 运用熵权法和数据包络 分析测算其 21 个地级市的绿色经济效率, 通过分析发现广东省绿色经济效率呈现下降趋势。 关于绿色经济效率影响因素分析的研究主要有: 钱争鸣 ${ }^{[5]}$ 研究发现环境规制对绿色经济效率 的影响具有“时滞性”和“非线性”, 随着环境规制的加强, 绿色经济效率呈现出先降后升趋势; 刘耀斌 ${ }^{[6]}$ 用系统广义矩阵方法实证研究了文化产业集聚对绿色经济效率的动态非线性影响关 系，发现文化产业集聚对绿色经济效率产生先抑制后促进的非线性关系，两者之间呈现出U型 曲线关系; 于伟 ${ }^{[7]}$ 在测度我国省域单元绿色经济效率的基础上, 分析空间互动状态下城市化进 程对绿色经济效率增长的影响。

综合以上可以发现，尽管学者们针对绿色经济发展进行的研究较为细致，但对于创新要 素投入与绿色经济效率关系的研究尚且较少, 且基于空间视角展开的研究更是少见, 因此本 文从空间视角探讨创新要素投入如何影响绿色经济效率的, 并对创新要素投入的空间溢出效 应进行实证分析。

\section{2. 研究设计}

\section{1 变量说明}

本文基于中国大陆 30个省/直辖市/自治区（西藏数据缺失，故除去）2009-2016年的省 际面板数据展开研究, 所有数据来源于《中国统计年鉴》、《中国科技统计年鉴》、《中国能 源统计年鉴》、《中国能源统计年鉴》及各省统计年鉴等。

被解释变量。本文用绿色经济效率（GEE）衡量全国30省绿色经济发展状况，绿色经济 效率的计算通常考虑四类指标：非资源投入要素（劳动力、资本）、资源投入要素（资源）、 
非期望产出（环境污染综合指数）、期望产出（地区生产总值）。其中，劳动力投入指标用年 末就业人数衡量, 资本投入指标用资本存量 ${ }^{[8]}$ 衡量, 资源投入指标用能源消耗总量折算成标准 煤衡量, 环境污染综合指数将各地区工业废水、工业废气排放量和工业固体废弃物产生量考 虑在内运用熵权法计算所得。

解释变量。本文从创新人员和创新资本两个方面测算创新要素投入量, 其中创新人员投 入 (PR) 用各地区研发人员全时当量的对数值衡量, 创新资本投入（CR）用各地区研发经费 内部支出的对数值衡量。

控制变量。本文依据以往研究结果, 选取三个控制变量, 一是经济发展水平（PGDP）, 用人均GDP表示; 二是外商直接投资（FDI），用地区历年外商直接投资除以地区GDP得到; 三是城镇化水平（URB），用城镇人口与地区总人口之比表示。

\section{2 构建模型}

\section{2 .1 空间相关性检验}

空间计量模型相较于传统计量模型的优势在于模型中体现了经济数据中普遍存在的空间 依赖性 ${ }^{[9]}$, 构建模型时若忽略变量的空间依赖性会导致估计结果有偏, 因此本文采取最为常用 的Moran's I指数衡量变量的空间相关性, 其计算方法如下:

$$
\text { Moran's I }=\frac{n \sum_{i=1}^{n} \sum_{j=1}^{n} w_{i j}\left(x_{i}-\bar{x}\right)\left(x_{j}-\bar{x}\right)}{\sum_{i=1}^{n} \sum_{j=1}^{n} w_{i j} \sum_{i=1}^{n}\left(x_{i}-\bar{y}\right)^{2}} \bar{x}=\frac{1}{n} \sum_{i=1}^{n} x_{i}
$$

式（1）中，表示第i个空间单位的观察值，表示标准化处理的空间权重矩阵，本文采用的 是一阶rook邻接矩阵。Moran's I为正值表示存在正向空间相关性, 为负值表示存在负向空间 相关性，且Moran's I指数的绝对值越大表示空间相关性越强。

表1给出了绿色经济效率的Moran's I指数, 从表中可以看出绿色经济效率的Moran's I指数 均为正值且通过 $5 \%$ 的显著性检验, 并呈现逐年增大的趋势, 说明各地区绿色经济效率存在显 著的正向空间相关性且这种相关性逐年增强，表明采用空间面板计量模型具有合理性。

表1 绿色经济效率的Moran's I指数

\begin{tabular}{|c|c|c|c|c|c|c|c|c|}
\hline 年份 & 2009 & 2010 & 2011 & 2012 & 2013 & 2014 & 2015 & 2016 \\
\hline $\mathrm{GEE}$ & $0.1418^{* *}$ & $0.1635^{* * *}$ & $0.1386^{* *}$ & $0.1271^{* *}$ & $0.2601^{* * *}$ & $0.2573^{* * *}$ & $0.2903^{* * *}$ & $0.2807^{* * *}$ \\
\hline 注: ${ }^{*}{ }^{* *}{ }^{* * *}$ 分别表示 $10 \% 、 5 \% 、 1 \%$ 的显著性水平，下同。 \\
\hline
\end{tabular}

\subsection{2 空间面板模型构建}

通过上文分析可以发现研究主体存在明显的空间相关性, 为避免估计偏误应采用空间面 板模型进行实证分析。目前应用较为广泛的空间计量模型有三种, 包括空间滞后模型 (SLM)、 空间误差模型（SEM）和空间杜宾模型（SDM）。SLM模型中空间相关性主要体现在被解释 变量的滞后项上, 侧重于研究邻近地区的行为对本地区产生的影响; SEM模型中空间相关性 主要体现在误差项的滞后项上，侧重于研究地区间通过误差项的相互关联建立联系的情况; $\mathrm{SDM}$ 模型将被解释变量滞后效应和误差项的滞后效应均考虑在内, 在面板数据的基础上对不 同个体产生的空间溢出效应能进行更好的估计，因此本文采用空间杜宾模型进行实证分析， 模型构建如下:

$$
G E E_{i t}=C+\rho W G E E+\beta_{1} P R_{i t}+\beta_{2} C R_{i t}+\sum_{n=3}^{5} \beta_{n} X_{i t}+\gamma_{1} C R_{i t}+\gamma_{2} C R_{i t}+\sum_{n=2}^{5} \gamma_{n} W X_{i t}+\varepsilon_{i t}
$$

式 (2) 中是指绿色经济效率指标, WGEE是被解释变量的空间滞后项, $\rho$ 是空间自相关 系数, $\beta$ 为解释变量和控制变量的回归系数, $X$ 为控制变量, 考察的是其他地区解释变量对本 地被解释变量的影响程度, PR和CR分别指创新人员投入和创新资本投入。 


\section{3. 实证结果与分析}

\section{1 空间计量结果分析}

表 2 是以绿色经济效率作为被解释变量进行的估计结果, 从表中可以看出调整后的 $\mathrm{R}^{2}$ 为 0.6745 , 且 $\log \mathrm{L}$ 的绝对值较大, 说明模型整体解释力度和拟合优度较好。空间滞后系数 $\mathrm{W}^{*}$ dep.var为 0.1279 但未能通过显著性检验, 说明我国各地区的绿色经济效率存在一定的正向 依赖性，即其他地区的绿色经济发展对本地区有一定正向促进作用，但这种作用不明显。创 新人员投入 (PR) 的系数为 -0.012 但未能通过显著性检验, 说明创新人员投入对绿色经济效率 无显著影响, 其空间项 $\mathrm{W} * \mathrm{PR}$ 的系数为 0.155 且在 $1 \%$ 水平上显著, 表示创新人员投入存在显著 的正向空间溢出效应; 创新资本投入 (CR) 的系数为 0.068 且通过 $5 \%$ 水平的显著性检验, 说明 创新资本投入对绿色经济效率存在显著的正向促进作用，其空间项 $\mathrm{W}^{*} \mathrm{CR}$ 的系数为 0.137 且通 过 $1 \%$ 水平的显著性检验, 说明创新资本投入存在显著的正向空间溢出效应。此外，外商直接 投资（FDI）、经济发展水平（PGDP）和城市化水平（URB）的系数不显著, 说明其对绿色 经济效率的影响不显著。

表2 SDM模型估计结果

\begin{tabular}{|c|c|c|c|c|c|c|c|c|c|c|}
\hline $\begin{array}{c}\text { 变 } \\
\text { 量 }\end{array}$ & $\begin{array}{c}\text { Ajusted } \\
-\mathrm{R}^{2}\end{array}$ & $\log \mathrm{L}$ & $\mathrm{W}^{*}$ dep.var & $\mathrm{PR}$ & $\mathrm{CR}$ & $\mathrm{FDI}$ & $\mathrm{PGDP}$ & $\mathrm{URB}$ & $\mathrm{W} * \mathrm{PR}$ & $\mathrm{W}^{*} \mathrm{CR}$ \\
\hline $\begin{array}{c}\text { 系 } \\
\text { 数 }\end{array}$ & 0.6745 & 322 & $\begin{array}{c}0.1279 \\
(1.519)\end{array}$ & $\begin{array}{c}-0.012 \\
(-0.41)\end{array}$ & $\begin{array}{c}0.068^{* *} \\
(2.46)\end{array}$ & $\begin{array}{c}-0.005 \\
(-1.37)\end{array}$ & $\begin{array}{c}0.009 \\
(0.33)\end{array}$ & $\begin{array}{c}0.148 \\
(1.57)\end{array}$ & $\begin{array}{c}0.155^{* * *} \\
(3.34)\end{array}$ & $\begin{array}{c}0.137^{* * *} \\
(-3.47)\end{array}$ \\
\hline 注: () 内为t 统计量的值, 下同。 \\
\hline
\end{tabular}

\section{2 空间效应分解}

为进一步了解创新要素投入对本地区和临近地区绿色经济发展的影响, 本文将空间效应 分解为直接效应、间接效应和总效应, 分解结果如表3 所示。

从表 3 可知，创新人员投入 (PR) 的直接效应系数为 -0.006 但不显著, 说明创新人员投入 对本地区绿色经济效率存在一定的抑制作用，但这种抑制作用不显著，原因可能是本地区创 新人员投入力度与绿色经济发展水平不相匹配, 导致新投入的创新人员边际贡献率递减, 其 间接效应的系数为 0.171 且在 $1 \%$ 水平上显著, 说明创新人员投入对邻近地区的绿色经济效率提 升有显著促进作用; 创新资本投入 (CR) 的直接效应系数为 0.062 且通过 $5 \%$ 水平的显著性检 验, 说明创新资本投入对本地区绿色经济效率的提升有明显的正向促进作用, 其间接效应系 数为 -0.168 且在 $1 \%$ 水平上显著, 说明创新资本投入对邻近地区绿色经济效率的提升有显著抑 制作用，原因可能是本地区绿色经济效率的提升会吸引邻近地区创新资本的流入，进而导致 邻近地区创新资本投入的贡献率降低。此外, 外商直接投资和城市化水平的直接效应系数和 间接效应系数均不显著, 说明外商直接投资和城市化水平对本地区和邻近地区的绿色经济效 率均无显著影响; 经济发展水平的直接效应系数不显著, 间接效应系数显著为正值, 说明经 济发展水平对邻近地区绿色经济效率的提升有正向促进作用。

表3 空间效应分解

\begin{tabular}{|c|c|c|c|c|c|}
\hline 变量 & $\mathrm{PR}$ & $\mathrm{CR}$ & $\mathrm{FDI}$ & $\mathrm{PGDP}$ & $\mathrm{URB}$ \\
\hline \multirow{2}{*}{ 直接效应 } & -0.006 & $0.062^{* *}$ & -0.005 & 0.013 & 0.135 \\
& $(-0.23)$ & $(2.27)$ & $(-1.34)$ & $(0.48)$ & $(1.38)$ \\
\hline \multirow{2}{*}{ 间接效应 } & $0.171^{* * * *}$ & $-0.168^{* * *}$ & -0.002 & $0.154^{* * *}$ & -0.379 \\
& $(3.23)$ & $(-3.17)$ & $(-0.20)$ & $(2.94)$ & $(-1.61)$ \\
\hline \multirow{2}{*}{ 总效应 } & $0.165^{* * *}$ & $-0.105^{*}$ & -0.007 & $0.168^{* *}$ & -0.243 \\
& $(2.94)$ & $(-1.86)$ & $(-0.59)$ & $(2.53)$ & $(-0.87)$ \\
\hline
\end{tabular}




\section{4. 结论与启示}

本文基于我国2009-2016年30省（除西藏）面板数据，采用非径向、非角度的SBM模型测 算绿色经济效率, 并人员和资本两个角度实证检验创新要素投入对绿色经济发展的影响, 研 究发现：（1）创新人员投入对本地区绿色经济发展无显著作用，但能正向促进邻近地区绿色 经济发展; (2) 创新资本投入对本地区绿色经济发展有显著促进作用, 但对邻近地区绿色经 济发展表现出抑制作用，且对临近地区的抑制作用大于对本地区的促进作用。（3）外商直接 投资和城市化进程对绿色经济效率的影响作用不显著, 经济发展水平能够促进邻近地区绿色 经济效率的提升。

为有效利用上述结论来促进区域绿色经济发展，本文提出如下建议：（1）鉴于创新人员 投入对本地区绿色经济发展无显著作用但对邻近地区有显著促进作用，因此应提高本地区绿 色经济发展水平与创新人员引进水平的匹配度, 确保创新人员引入与本地区要素禀赋结构相 适应，对于绿色经济发展水平相对较高的地区，要适当向周边地区转移高技术人才，对于绿 色经济发展水平相对较低的地区，应强化人才战略，主动引进高技术人才; (2) 鉴于创新资 本对本地区有促进作用，对邻近地区有抑制作用，因此对处于绿色经济发展水平较高地区的 周边区域要加强创新资本引进力度，积极拓展创新资本引进渠道，打破固有经济体制和思想 观念的束缚, 建设开放型经济体制, 提高创新资本引进效率; （3）鉴于经济发展水平能够提 高邻近地区绿色经济效率，应该加强邻近地区市场经济体制的完善，促进这些地区经济水平 的快速提升。

\section{致谢}

本文为中国高等教育学会“中国高等教育改革发展重大理论实践问题研究”课题“高校服 务国家战略需要和区域经济社会发展研究”（2017ZD006）的阶段性成果之一。

\section{References}

[1] Hailu.A, Veeman, T.S, Environmentally Sensitive Productivity Analysis of the Canadian Pulp and Paper Industry, 1959-1994: An Input Distance Function Approach, Journal of Environmental Economics\&Management, vol.40, pp. 251-274, 2000.

[2] Ye Rendao, Zhang Yong and Luo Kun, Calculation and influence factors of Green Economic Efficiency of China: Based on Skew-normal panel data model, Technical Economy, vol.36, pp. 79-85, 2017.

[3] Nie Yuli and Wen Huwei, Green Economic Efficiency of Chinese City at the Level of Municipality or Above, Chinese population, vol.25, pp. 409-413, 2015.

[4] Zhang Jun and Dian Jie, Calculation and Empirical Study of Green Economic Efficiency in Guangdong Province, Ecology Economy, vol. 33, pp. 12-18, 2015.

[5] Qian Zhengming and Liu Xiaochen, Environmental Regulation and Green Economic Efficiency, Statistical research, vol. 32, pp. 12-18, 2015.

[6] Liu Yaobin, Yuan Huaxi and Wangji, The impact of cultural industry agglomeration on the efficiency of green economy: An Empirical Analysis Based on Dynamic Panel Model, Resource Science, vol. 39, pp. 747-755, 2017.

[7] Yu wei and Zhang peng, Urbanization process, spatial spillover and green economic efficiency growth: a spatial econometric study based on provincial units in 2002-2012, inquiry into economic issues, vol. 1, pp. 77-82, 2016. 
[8] Zhang jun, Wu Guiying and Zhang Jipeng, The Estimation of China's provincial capital stock: 1952-2000, economic research, vol. 10, pp. 77-82, 2016.

[9] Anselin L. Spatial econometrics: Methods and mode-ls, Netherland: Kluwer academic publishers, 1988. 